\title{
Research on the Competition Strategy of the Fresh Agricultural Products based on Hotelling Model
}

\author{
Jie Zhou \\ School of Management, East China University of \\ Science and Technology \\ Shanghai, China \\ E-mail: jessiechou0710@163.com
}

\author{
Tijun Fan \\ School of Management, East China University of \\ Science and Technology \\ Shanghai, China \\ E-mail: tjfan@ecust.edu.cn
}

\begin{abstract}
With the rapid de velopment of e-commerce, fresh agricultural products have gradually begun to develop ecommerce market. However, fresh agricultural products are perishable in the process of transportation and sales. Based on Hotelling model, this paper studies how an electronic retailer make price and distribution decisions to compete with a traditional retailer in a linear city, considering the conditions of fresh agricultural products freshness influence consumer utility. The result shows that only when the cost difference between the two retailers is large enough, the electronic retailer can improve equilibrium profit by improve the distribution speed. And if the cost difference between the two retailers are small or large enough while the per unit distance transportation cost is large, electronic retailer can improve equilibrium profit through increase unit distance transportation cost.
\end{abstract}

Keywords- Hotelling Model; Electronic Retailer; Fresh agriculture product; Freshness.

\section{INTRODUCTION}

In recent years, with the rapid development of China's economy and the support of the enterprise informationization, e-commerce has been developed rapidly. According to the statistics of China Internet Network Center (CNNIC), as of December 2013, the network shopping user scale reached 302 million, netizens use rate increased to $48.96 \%$. That means about half of all Internet users have online shopping experience. The amount of market transactions growth rapidly and the type of goods is also far richer than ten years ago. Online shopping has become a shopping channel which netizens cannot live without.

The great potential of network shopping attracts many enterprises in various industries to join the E-commerce, and form the coexistence of the electronic retail channel and the traditional retail channel. The electronic retail channels of fresh agricultural products have emerged in recent years, but it is not mature and stable. As fresh agricultural products are fast-moving consumer products, the supply and demand is not very stable and its own characteristics of perishable, seas onal, seasonal, regional, random short life cycle restrict the whole supply chain circulation process. If the fresh agricultural products can rely on online shopping to seize a share of the market, to better according to the market in the allocation of resources to a new pattern of agricultural economy form, help to solve farmers selling vegetables difficult, low income problem, and further to meet the needs of consumers on the quality of fresh agricultural products on the market. How to make electronic retail channels of fresh agricultural products occupy a certain market share, the fresh agricultural products electronic retail channels in the face of traditional retail channels how to improve their competitiveness has become the one of the important problems of fresh agricultural product electronic commerce development.

The research of this paper is divided into two aspects. One is study on the supply chain of fresh agricultural products. Cai et al distributors preservation efforts by introducing concepts discussed include a single manufacturer, a single secondary distributors of fresh produce supply chain are optimal decisions in a decentralized decision-making model and centralized decision-making model, and using data analysis to verify the distributors preservation efforts expected return on supply chain positive externalities; Chen Jian et al studied the specific business model involving long-distance transport CIF of fresh produce supply chain, taking into account the manufacturer undertake long-distance transport of uncertainty and risk the manufacturer of the consumer market, the establishment of a three-stage decision model supply chain, and cost-sharing mechanism designed to coordinate them. Although the above literature studies the loss of fresh agricultural products from different perspectives, there is no fresh agricultural ecommerce channel to consider.

The other is about the Hotelling model. Harter explored the situation that the consumer preference is not certain. $\mathrm{He}$ draws a conclusion that to maximize the product difference in order to avoid the fierce price competition. Xinjun Diao analyzed the Hotelling model with uncertain consumer preference, turns out that the greater the uncertainty, the greater difference the manufacturer's profit, price and product. But there is little research on fresh agriculture products using Hotelling model.

In summary, the supply chain of fresh agricultural products has little research on the traditional retail channels and electronic retail channels of the two channels of retailers. Therefore, based on Hotelling model, this paper studies the sales of fresh agricultural products traditional retailers and e-tailers who are located at both ends of the linear city, traditional retailers and e-tailers equilibrium price and profit, and electronics retailers face 
traditional retailers to compete on the distribution of velocity and distance distribution costs of the decision problem.

\section{MODEL AND HYPOTHESIS}

Assuming that there is a linear city with a length of 1 , consumers are distributed evenly on the line segments. A traditional retailer 1 is in the position of the segment of the left (position 0), and the electronic retailer 2 is located at the segment of the right (position 1). They sell same products with different unit $\operatorname{cost} c_{1}, c_{2}$ and price $p_{1}$ and $p_{2}$ respectively (usually we assume that $c_{1}>c_{2}$ )). They set their selling prices at the same time. The unit travel cost, travel speed and time needed for consumers going to traditional retail store are $\mathrm{d}_{1}, \mathrm{v}_{1}$ and $\mathrm{t}_{1}$ respectively. Meanwhile, the unit travel cost, distribution speed and time needed for consumers getting the products from the electronic retailer store are $\mathrm{d}_{2}, \mathrm{v}_{2}$ and $\mathrm{t}_{2}$ respectively. It is obvious that $v_{1} t_{1}+v_{2} t_{2}=1$. Considering the reality that the speed of consumers going to the traditional retail store is often faster than the speed of the electronic retailer distribute products to consumer through the delivery to the consumer, so we assume that $v_{1}>v_{2}$. The utility of the consumer purchasing product is related to the retail price of the product and the freshness of the product obtained. The fresh degree function is given by: $\theta(t)=1-\frac{t}{T}$ (where $\mathrm{T}$ denotes the shelf life of the product and $t$ denotes the time required for consumers to obtain the product. As to simplify the model, we assume that when consumers choose to purchase the products, the freshness of the product is 1).

The customer is indifferent between the stores (the traditional retail store and the electronic retail store) when

$$
\begin{aligned}
\theta\left(1-\frac{\mathrm{t}_{1}}{\mathrm{~T}}\right)-\mathrm{p}_{1} & -\mathrm{d}_{1} \mathrm{v}_{1} \mathrm{t}_{1} \\
= & \theta\left(1-\frac{1-\mathrm{v}_{1} \mathrm{t}_{1}}{\mathrm{v}_{2} \mathrm{~T}}\right)-\mathrm{p}_{2} \\
& -\mathrm{d}_{2}\left(1-\mathrm{v}_{1} \mathrm{t}_{1}\right)
\end{aligned}
$$

The left hand side and right hand side of this equation model the traditional retail store and the electronic retail store respectively.

The customer's location( $\left(\mathrm{t}_{1}^{*}\right)$ corres ponding to the above is given by:

$$
\mathrm{t}_{1}^{*}=\frac{\left(\mathrm{p}_{2}-\mathrm{p}_{1}+\mathrm{d}_{2}\right) \mathrm{v}_{2} \mathrm{~T}+\theta}{\left(\mathrm{d}_{1}+\mathrm{d}_{2}\right) \mathrm{v}_{1} \mathrm{v}_{2} \mathrm{~T}+\theta\left(\mathrm{v}_{1}+\mathrm{v}_{2}\right)}
$$

For the traditional retail store, the objective is to maximize the profit function given by:

$$
\begin{aligned}
\pi_{1}=\left(p_{1}-c_{1}\right) D_{1} & =\left(p_{1}\right. \\
& \left.-c_{1}\right) \frac{\left(p_{2}-p_{1}+d_{2}\right) v_{1} v_{2} T+\theta v_{1}}{\left(d_{1}+d_{2}\right) v_{1} v_{2} T+\theta\left(v_{1}+v_{2}\right)}
\end{aligned}
$$

For the electronic retail store, the objective is to maximize the profit function given by:

$\pi_{2}=\left(p_{2}-c_{2}\right) D_{2}$

$$
\begin{aligned}
& =\left(\mathrm{p}_{2}\right. \\
& \left.-\mathrm{c}_{2}\right) \frac{\left(\mathrm{p}_{1}-\mathrm{p}_{2}+\mathrm{d}_{1}\right) \mathrm{v}_{1} \mathrm{v}_{2} \mathrm{~T}+\theta \mathrm{v}_{2}}{\left(\mathrm{~d}_{1}+\mathrm{d}_{2}\right) \mathrm{v}_{1} \mathrm{v}_{2} \mathrm{~T}+\theta\left(\mathrm{v}_{1}+\mathrm{v}_{2}\right)}
\end{aligned}
$$

Taking the first derivative of $\pi_{1}$ with respect to $p_{1}$ and first derivative of $\pi_{2}$ with respect to $\mathrm{p}_{2}$ :

$$
\frac{\partial \pi_{1}}{\partial p_{1}}=\frac{\left(p_{2}-2 p_{1}+d_{2}+c_{1}\right) v_{1} v_{2} T+\theta v_{1}}{\left(d_{1}+d_{2}\right) v_{1} v_{2} T+\theta\left(v_{1}+v_{2}\right)}
$$

$$
\frac{\partial \pi_{2}}{\partial \mathrm{p}_{2}}=\frac{\left(\mathrm{p}_{1}-2 \mathrm{p}_{2}+\mathrm{d}_{1}+\mathrm{c}_{2}\right) \mathrm{v}_{1} \mathrm{v}_{2} \mathrm{~T}+\theta \mathrm{v}_{2}}{\left(\mathrm{~d}_{1}+\mathrm{d}_{2}\right) \mathrm{v}_{1} \mathrm{v}_{2} \mathrm{~T}+\theta\left(\mathrm{v}_{1}+\mathrm{v}_{2}\right)}
$$

Make $\frac{\partial \pi_{1}}{\partial \mathrm{p}_{1}}=0, \frac{\partial \pi_{2}}{\partial \mathrm{p}_{2}}=0$, then solve for $\mathrm{p}_{1}^{*}$ and $\mathrm{p}_{2}^{*}$ :

$\mathrm{p}_{1}^{*}=\frac{\left(\mathrm{d}_{1}+2 \mathrm{~d}_{2}+2 \mathrm{c}_{1}+\mathrm{c}_{2}\right) \mathrm{v}_{1} \mathrm{v}_{2} \mathrm{~T}+\theta\left(2 \mathrm{v}_{1}+\mathrm{v}_{2}\right)}{3 \mathrm{v}_{1} \mathrm{v}_{2} \mathrm{~T}}$

$\mathrm{p}_{2}^{*}=\frac{\left(2 \mathrm{~d}_{1}+\mathrm{d}_{2}+\mathrm{c}_{1}+2 \mathrm{c}_{2}\right) \mathrm{v}_{1} \mathrm{v}_{2} \mathrm{~T}+\theta\left(\mathrm{v}_{1}+2 \mathrm{v}_{2}\right)}{3 \mathrm{v}_{1} \mathrm{v}_{2} \mathrm{~T}}$

Put the $\mathrm{p}_{1}^{*}$ and $\mathrm{p}_{2}^{*}$ into the demand function:

$$
\begin{aligned}
& \mathrm{D}_{1}^{*}=\frac{\left(\mathrm{d}_{1}+2 \mathrm{~d}_{2}+\mathrm{c}_{2}-\mathrm{c}_{1}\right) \mathrm{v}_{1} \mathrm{v}_{2} \mathrm{~T}+\theta\left(2 \mathrm{v}_{1}+\mathrm{v}_{2}\right)}{3\left[\left(\mathrm{~d}_{1}+\mathrm{d}_{2}\right) \mathrm{v}_{1} \mathrm{v}_{2} \mathrm{~T}+\theta\left(\mathrm{v}_{1}+\mathrm{v}_{2}\right)\right]} \\
& \mathrm{D}_{2}^{*}=\frac{\left(2 \mathrm{~d}_{1}+\mathrm{d}_{2}+\mathrm{c}_{1}-\mathrm{c}_{2}\right) \mathrm{v}_{1} \mathrm{v}_{2} \mathrm{~T}+\theta\left(\mathrm{v}_{1}+2 \mathrm{v}_{2}\right)}{3\left[\left(\mathrm{~d}_{1}+\mathrm{d}_{2}\right) \mathrm{v}_{1} \mathrm{v}_{2} \mathrm{~T}+\theta\left(\mathrm{v}_{1}+\mathrm{v}_{2}\right)\right]}
\end{aligned}
$$

As the demand function mustn't be negative, make $\mathrm{D}_{1}^{*} \geq 0, \quad \mathrm{D}_{2}^{*} \geq 0$ :

$$
\begin{gathered}
\mathrm{c}_{1}-\mathrm{c}_{2} \leq \mathrm{d}_{1}+2 \mathrm{~d}_{2}+\frac{\theta\left(2 \mathrm{v}_{1}+\mathrm{v}_{2}\right)}{\mathrm{v}_{1} \mathrm{v}_{2} \mathrm{~T}} \\
\pi_{1}^{*}=\frac{\left[\left(\mathrm{d}_{1}+2 \mathrm{~d}_{2}+\mathrm{c}_{2}-\mathrm{c}_{1}\right) \mathrm{v}_{1} \mathrm{v}_{2} \mathrm{~T}+\theta\left(2 \mathrm{v}_{1}+\mathrm{v}_{2}\right)\right]^{2}}{9 \mathrm{v}_{1} \mathrm{v}_{2} \mathrm{~T}\left[\left(\mathrm{~d}_{1}+\mathrm{d}_{2}\right) \mathrm{v}_{1} \mathrm{v}_{2} \mathrm{~T}+\theta\left(\mathrm{v}_{1}+\mathrm{v}_{2}\right)\right]} \\
\pi_{2}^{*}=\frac{\left[\left(2 \mathrm{~d}_{1}+\mathrm{d}_{2}+\mathrm{c}_{1}-\mathrm{c}_{2}\right) \mathrm{v}_{1} \mathrm{v}_{2} \mathrm{~T}+\theta\left(\mathrm{v}_{1}+2 \mathrm{v}_{2}\right)\right]^{2}}{9 \mathrm{v}_{1} \mathrm{v}_{2} \mathrm{~T}\left[\left(\mathrm{~d}_{1}+\mathrm{d}_{2}\right) \mathrm{v}_{1} \mathrm{v}_{2} \mathrm{~T}+\theta\left(\mathrm{v}_{1}+\mathrm{v}_{2}\right)\right]}
\end{gathered}
$$

\section{CONCLUSION AND ANALYSIS}

\section{A. Analysis of the impact of electronic retailer's delivery speed $v_{2}$ on two retailers}

The growth of the private technology enterprise depends on the financing. However, in the process of development, financing is the major problem for most private technology enterprises ${ }^{[5-6]}$. According to the questionnaire of Shanghai private technology enterprise, we find that financing situation of Shanghai private technology enterprises present the following features:

Proposition 1 . With the increase of delivery speed, the increase speed of demand of electronic retailer decline, which means consumers' sensitivity of delivery speed decrease with the increase of delivery speed.

$$
\begin{aligned}
& \text { Proof. } \\
& \frac{\partial \mathrm{D}_{2}^{*}}{\partial \mathrm{v}_{2}}=\frac{\theta\left[\left(\mathrm{d}_{1}+\mathrm{c}_{1}-\mathrm{c}_{2}\right) \mathrm{v}_{1}^{2} \mathrm{~T}+\theta \mathrm{v}_{1}\right]}{3\left[\left(\mathrm{~d}_{1}+\mathrm{d}_{2}\right) \mathrm{v}_{1} \mathrm{v}_{2} \mathrm{~T}+\theta\left(\mathrm{v}_{1}+\mathrm{v}_{2}\right)\right]^{2}}>0 \\
& \frac{\partial \mathrm{D}_{2}^{* 2}}{\partial^{2} \mathrm{v}_{2}}=-\frac{\left[\left(\mathrm{d}_{1}+\mathrm{c}_{1}-\mathrm{c}_{2}\right) \mathrm{v}_{1}^{2} \mathrm{~T}+\mathrm{v}_{1}\right]\left[\left(\mathrm{d}_{1}+\mathrm{d}_{2}\right) \mathrm{v}_{1} \mathrm{~T}+1\right]}{3\left[\left(\mathrm{~d}_{1}+\mathrm{d}_{2}\right) \mathrm{v}_{1} \mathrm{v}_{2} \mathrm{~T}+\mathrm{v}_{1}+\mathrm{v}_{2}\right]^{3}} \\
& <0
\end{aligned}
$$

By the formulation above we can see the increase speed of demand of electronic retailer decline with the increase of delivery speed.

Proposition 2. When $0<\mathrm{c}_{1}-\mathrm{c}_{2}<\mathrm{d}_{2}+\frac{\theta}{\mathrm{v}_{2} \mathrm{~T}}$, both retailers; profit may decrease with the increase of delivery speed. When $\mathrm{d}_{2}+\frac{\theta}{\mathrm{v}_{2} \mathrm{~T}}<c_{1}-\mathrm{c}_{2}<\mathrm{d}_{1}+2 \mathrm{~d}_{2}+$ $\frac{\theta\left(2 v_{1}+v_{2}\right)}{v_{1} v_{2} T}$, with the increase of the delivery speed, the profit of the electronic retailer increases and the profit of the traditional retailer decreases.

Proof.

$$
\frac{\partial \pi_{1}^{*}}{\partial \mathrm{v}_{2}}=-\frac{{ }^{[}\left[\left(2 \mathrm{~d}_{1}+\mathrm{d}_{2}+\mathrm{c}_{1}-\mathrm{c}_{2}\right) \mathrm{v}_{1} \mathrm{v}_{2} \mathrm{~T}+\mathrm{v}_{1}+2 \mathrm{v}_{2}\right]\left[\left(\mathrm{d}_{2}+\mathrm{c}_{2}-\mathrm{c}_{1}\right) \mathrm{v}_{1}{ }^{3} \mathrm{v}_{2} \mathrm{~T}^{2}+\theta \mathrm{v}_{1}{ }^{3} \mathrm{~T}\right]}{9 \mathrm{v}_{1}{ }^{2} \mathrm{v}_{2}{ }^{2} \mathrm{~T}^{2}\left[\left(\mathrm{~d}_{1}+\mathrm{d}_{2}\right) \mathrm{v}_{1} \mathrm{v}_{2} \mathrm{~T}+\mathrm{v}_{1}+\mathrm{v}_{2}\right]^{2}}<0
$$

As can be seen, when the electronic retailer's delivery increase, the profit of the traditional retailer decreases. 


$$
\frac{\partial \pi_{1}^{*}}{\partial \mathrm{v}_{2}}=-\frac{{ }_{\theta}\left[\left(2 \mathrm{~d}_{1}+\mathrm{d}_{2}+\mathrm{c}_{1}-\mathrm{c}_{2}\right) \mathrm{v}_{1} \mathrm{v}_{2} \mathrm{~T}+\mathrm{v}_{1}+2 \mathrm{v}_{2}\right]\left[\left(\mathrm{d}_{2}+\mathrm{c}_{2}-\mathrm{c}_{1}\right) \mathrm{v}_{1}{ }^{3} \mathrm{v}_{2} \mathrm{~T}^{2}+\theta \mathrm{v}_{1}{ }^{3} \mathrm{~T}\right]}{9 \mathrm{v}_{1}{ }^{2} \mathrm{v}_{2}{ }^{2} \mathrm{~T}^{2}\left[\left(\mathrm{~d}_{1}+\mathrm{d}_{2}\right) \mathrm{v}_{1} \mathrm{v}_{2} \mathrm{~T}+\mathrm{v}_{1}+\mathrm{v}_{2}\right]^{2}}<0
$$

To make $\frac{\partial \pi_{2}^{*}}{\partial \mathrm{v}_{2}}>0$, there must be $\mathrm{d}_{2}+\frac{\theta}{\mathrm{v}_{2} \mathrm{~T}}<c_{1}-\mathrm{c}_{2}<$ $\mathrm{d}_{1}+2 \mathrm{~d}_{2}+\frac{\theta\left(2 \mathrm{v}_{1}+\mathrm{v}_{2}\right)}{\mathrm{v}_{1} \mathrm{v}_{2} \mathrm{~T}}$; to make $\frac{\partial \pi_{2}^{*}}{\partial \mathrm{v}_{2}}<0$, there must be $\mathrm{d}_{2}+\frac{\theta}{\mathrm{v}_{2} \mathrm{~T}}<c_{1}-\mathrm{c}_{2}<\mathrm{d}_{1}+2 \mathrm{~d}_{2}+\frac{\theta\left(2 \mathrm{v}_{1}+\mathrm{v}_{2}\right)}{\mathrm{v}_{1} \mathrm{v}_{2} \mathrm{~T}}$.

From Proposition 2 we can see, for electronic retailer, when the unit cost differences between the two retailers is large enough $\left(\mathrm{d}_{2}+\frac{\theta}{\mathrm{v}_{2} \mathrm{~T}}<c_{1}-\mathrm{c}_{2}<\mathrm{d}_{1}+2 \mathrm{~d}_{2}+\right.$ $\left.\frac{\theta\left(2 v_{1}+v_{2}\right)}{v_{1} v_{2} T}\right)$, the electronics retailer can seize more part of market share, so that the profit may increase. When the difference of unit cost between two retailers is small $\left(0<c_{1}-c_{2}<d_{2}+\frac{\theta}{v_{2} T}\right)$, if the electronic retailer imp rove delivery speed, which makes $v_{2}$ approach $v_{1}$, may lead to the decline of difference between two retailers' products. That may lead to fierce competition between them and then reduce the profit.

Therefore, electronic retailers, only when the cost difference between the two retailers meet $\mathrm{d}_{2}+\frac{\theta}{\mathrm{v}_{2} \mathrm{~T}}<c_{1}-$ $c_{2}<d_{1}+2 d_{2}+\frac{\theta\left(2 v_{1}+v_{2}\right)}{v_{1} v_{2} T}$, the electronic retailer can increase profit through increase delivery speed.

\section{B. Analysis of the impact of electronic retailer's unit distribution cost $d_{2}$ on two retailers}

Proposition 3. With the increase of unit distribution cost, the traditional retailer's profit keeps increasing. If $0<\mathrm{c}_{1}-\mathrm{c}_{2}<\frac{\theta}{\mathrm{v}_{2} \mathrm{~T}}$, the electronic retailer's profit increases when $\mathrm{d}_{2}$ increases. If $\mathrm{c}_{1}-\mathrm{c}_{2}>\frac{\theta}{\mathrm{v}_{2} \mathrm{~T}}$, when $0<\mathrm{d}_{2}<\mathrm{c}_{1}-$ $c_{2}-\frac{\theta}{v_{2} T}$, the electronic retailer's profit is reduced when $d_{2}$ increase; when $d_{2}>c_{1}-c_{2}-\frac{\theta}{v_{2} T}$, the electronics retailer's profit increases when $d_{2}$ increase.

Proof. Similar to Proposition 2.

Proposition 3 shows that when unit cost difference between the two retailers is small $\left(0<c_{1}-c_{2}<\frac{\theta}{v_{2} T}\right)$, if unit distance transportation cost increase, the substitution between two retailer decreases and the differentiation between two retailers increases. So that both retailers strengthen the monopoly of the nearby consumers and obtain more profit. When unit cost difference between the two retailers is large enough $\left(c_{1}-c_{2}>\frac{\theta}{v_{2} T}\right)$, if $d_{2}$ is small $\left(0<\mathrm{d}_{2}<\mathrm{c}_{1}-\mathrm{c}_{2}-\frac{\theta}{\mathrm{v}_{2} \mathrm{~T}}\right)$, when $\mathrm{d}_{2}$ increases, though the strengthened monopoly can increase the profit, it still cannot cover the profit loss caused by the decrease of demand. So the profit will decrease. However, if $d_{2}$ is large $\left(d_{2}>c_{1}-c_{2}-\frac{\theta}{v_{2} T}\right)$, when $d_{2}$ increases, the profit of electronic retailer increases.
Therefore, if the cost difference between the two retailers is small $\left(0<\mathrm{c}_{1}-\mathrm{c}_{2}<\frac{\theta}{\mathrm{v}_{2} \mathrm{~T}}\right)$ or large enough while the per unit distance transportation cost is large $\left(c_{1}-c_{2}>\frac{\theta}{v_{2} T}, d_{2}>c_{1}-c_{2}-\frac{\theta}{v_{2} T}\right)$, both retailers can improve equilibrium profit through increase unit distance transportation cost.

\section{DISCUSSION}

Based on Hotelling model, this paper studies how a electronic retailer makes the price and distribution decisions to compete with a traditional retailer in a linear city, considering the conditions of fresh agricultural products freshness influence consumer utility. The result shows that only when the cost difference between the two retailers is large enough $\left(\mathrm{d}_{2}+\frac{\theta}{\mathrm{v}_{2} \mathrm{~T}}<c_{1}-\mathrm{c}_{2}<\mathrm{d}_{1}+\right.$ $\left.2 d_{2}+\frac{\theta\left(2 v_{1}+v_{2}\right)}{v_{1} v_{2} T}\right)$, the electronic retailer can improve equilibrium profit by improve the distribution speed. And if the cost difference between the two retailers is small $\left(0<c_{1}-c_{2}<\frac{\theta}{v_{2} T}\right)$ or large enough while the per unit distance transportation cost is large $\left(c_{1}-c_{2}>\frac{\theta}{v_{2} T}\right.$, $\mathrm{d}_{2}>\mathrm{c}_{1}-\mathrm{c}_{2}-\frac{\theta}{\mathrm{v}_{2} \mathrm{~T}}$ ), electronic retailer can improve equilibrium profit through increase unit distance transportation cost. However, this paper only considers one condition that consumers pay for the distribution cost and ignore the difference between consumers on the sensitivity of the freshness of fresh agriculture products. Therefore, classifying the consumers by the degree of sensitivity of the freshness of the consumer or retailer sharing the distribution cost may be the further research direction.

\section{REFERENCES}

[1] Cai, X. Q., J. Chen, Y. B. Xiao, et al. Optimization and Coordination of Fresh Product Supply Chains with FreshnessKeeping Effort[J]. Production and Operations Management, 2010, 19(3): 261-278.

[2] Yongbo Xiao, J. Chen, Xiaolin Xu. Fresh product supply chain coordination with long distance transportation under CF business model[J]. System engineering theory and Practice, 2008, 28(2):1925.

[3] Harter J.F.R Hotelling's competition with Demand location Uncertainty $[\mathrm{J}]$. International of industrial Organization, 1996,15(6):327-334.

[4] Xinjun Diao et. al. Competitive strategy of the double oligopoly enterprises under the uncertain consumer preference[J]. Systems engineering, 2008,26(8):93-96.

[5] Selwyn Piramuthu et. al. Should retail stores also RFID-tag 'cheap' items?[J]. European Journal of Operational Research, 233(2014):281-291

[6] Jeffrey D. Shulman, Xianjun Geng. Add-on Pricing by Asymmetric Firms[J]. Management Science, vol59, No4, April 2013:899-917.

[7] Jing Chen et. al. Implementing coordination contracts in a manufacturer Stackelberg dual-channel supply chain[J].Omega 20(2012):571-583

[8] Genesh lyer et. al. Information and Inventory in Distribution Channels[J]. Management Science 53(10):1551-1561. 